\title{
Borlanmış Hardox 500 Çeliklerin Aşınma Davranışlarının Incelenmesi
}

\section{Investigation of Wear Behavior of Boronized Hardox 500 Steels}

Geliş / Received: 03/01/2021

\author{
Rıza Kara $^{1 *}$, Yusuf Kayalı², Fatih Çolak ${ }^{3}$
}

$\overline{\text { ÖZ }}$

Revize / Revised: 01/03/2021

Kabul / Accepted: 02/03/2021

Bu çalışmada, aşınma direnci ve mekanik özellikleri ile dikkat çeken Hardox 500 çelikleri farklı sıcaklıklarda ve sürelerde kutu borlama işlemine tabi tutulmuştur. Borlama işlemi 850,900 ve $950{ }^{\circ} \mathrm{C}$ sicaklıklarda ve her bir borlama sıcaklığ için 2, 4 ve 6 saat süre ile gerçekleştirilmiştir. Borlama işleminin sonucunda numune yüzeylerinde oluşan bor tabakasının morfolojisi SEM mikroskobu ile incelenmiştir. Vickers sertlik değerleri ölçülerek oluşan bor fazları X-Ray kırınım tekniği (XRD) ile analiz edilmiştir. XRD analizine göre oluşan borür tabakasının tek fazlı $\mathrm{Fe}_{2} \mathrm{~B}$ yapısından oluştuğunu gözlemlenmiştir. Artan borlama sıcaklığı ve süresi ile Hardox 500 çeliğinde borür tabaka kalınlığının arttığı görülmüştür. Aşınma testleri, kuru bir ortamda ve 500 metrelik bir kayma mesafesinde 10 N'luk bir yük altında $0,3 \mathrm{~m} / \mathrm{s}^{\prime}$ lik bir kayma hızında bilyeli disk aşınma yöntemi kullanılarak gerçekleştirilmiştir. Borlama işlemi sonrasında yapılan aşınma deneyi sonucunda Hardox 500 çeliğinin aşınma hızı satın alındığı duruma göre azalmış aşınma direnci ise artmıştır. Borür tabakasının yapışma özellikleri DaimlerBenz Rockwell-C testi ile incelenmiştir. Borlama sıcaklığı ve süresinin artmasılyla aşınma ve yapışma direncinin azaldı̆̆ 1 tespit edilmiştir.

Anahtar Kelimeler- Hardox 500, Kutu Borlama, Aşınma, Rockwell-C

\begin{abstract}
In this study, Hardox 500 steels, which draw attention with their wear resistance and mechanical properties, were subjected to box boring process at different temperatures and times. Boronizing process was carried out at 850 , 900 and $950{ }^{\circ} \mathrm{C}$ temperatures and for 2, 4, and 6 hours for each boring temperature. The morphology of the boron layer formed on the sample surfaces as a result of the boronization process was examined by SEM microscope. Boron phases formed by measuring the Vickers hardness values were analyzed by X-Ray diffraction technique (XRD). It was observed that the boride layer formed according to the XRD analysis consisted of a single phase $\mathrm{Fe}_{2} \mathrm{~B}$ structure. It was observed that the boride layer thickness in Hardox 500 steel increased with the increasing boronization temperature and duration. The abrasion tests were carried out using the ball disc wear method at a sliding speed of $0.3 \mathrm{~m} / \mathrm{s}$ under a load of $10 \mathrm{~N}$ in a dry environment and a sliding distance of 500 meters. As a result of the abrasion test performed after the boronization process, the wear rate of Hardox 500 steel decreased compared to the purchased state, and the wear resistance increased. The adhesion properties of the boride layer were examined by the Daimler-Benz Rockwell-C test. It was determined that with increasing boronization temperature and time, the wear and adhesion resistance decreased.
\end{abstract}

Keywords- Hardox 500, Pack Boriding, Wear, Rockwell-C

\footnotetext{
1*Sorumlu yazar iletişim: riza.kara@usak.edu.tr (https://orcid.org/0000-0002-0820-2577)

Makine ve Metal Teknolojileri Bölümü, Ușak Üniversitesi, Teknik Bilimler Meslek Yüksek Okulu, Ușak, Türkiye

2illetişim: iykayali@aku.edu.tr (https://orcid.org/0000-0002-2449-7125)

Metalurji ve Malzeme Mühendisliği Bölümü, Afyon Kocatepe Üniversitesi, Teknoloji Fakültesi, Afyon, Türkiye

İletişim: fatih.colak@usak.edu.tr (https://orcid.org/0000-0002-1161-9875)
}

Makine ve Metal Teknolojileri Bölümü, Uşak Üniversitesi, Teknik Bilimler Meslek Yüksek Okulu, Uşak, Türkiye 


\section{GíRiş}

Mükemmel aşınma direnci, tokluk ve sertlik özellikleri ile Hardox çelikleri özellikle taşıyıcı, eleyici, yükleyici presler ve kırıcı gibi ağır iş makinelerinde yaygın bir kullanım alanı bulmaktadır. Sahip oldukları yüksek sertlikle beraber iyi tokluk özellikleri ile kalıcı deformasyon göstermeden ağır yüklemelere ve darbelere karşı dayanıklıdırlar [1-4]. Hardox 500 çelikleri martenzitik faz yapısına sahip malzemelerdir. Hardox 500 çelikleri 470$530 \mathrm{HB}$ sertlik, $-40{ }^{\circ} \mathrm{C}$ ' de 37 Joule çentik darbe dayanımı ve yaklaşı $1400 \mathrm{MPa}$ akma dayanımı ile ilgi çekmektedir. Ancak Hardox 500 çelikleri $250{ }^{\circ} \mathrm{C}$ ' ye kadar bu mekanik değerlerini koruyabilir [3]. Hardox çeliklerinin çarpma mukavemeti ve plastik esnekliği çok yüksektir [5]. Mekanik parçaların aşınması incelendiğinde büyük oranda abrasiv ve adhesion aşınma mekanizması ile hasara uğramaktadır. Bu oranın yaklaşık\% 65'si abrasiv ve adhesion aşınması oluşturmaktadır. Geri kalan hasar mekanizmasında diğger aşınma mekanizmaları etkendir [1].

Aşınma ve korozyon mekanizmaları ile yüzey malzemesi kaybı ortaya çıkmaktadır [2]. Bu olumsuz etkileri ortadan kaldırabilmek için malzeme yüzey işlemleri en yaygın modifikasyon yöntemlerindendir. Genel olarak, demir esaslı metallerin yüzey özelliklerini geliştirmek için sementasyon, nitrürleme veya borlama işlemleri yaygın olarak kullanılmaktadır [6,7]. Malzemelere uygulanan yüzey kaplama uygulamaları ile kullanım ömürlerinin arttırılması yaygın bir metottur $[6,8]$.

Borlama işlemi genellikle $700-1000{ }^{\circ} \mathrm{C}$ yüksek sıcaklıklar aralığında çeliğe bor atomlarının yayınımı işlemidir. Borlama işlemi bu sıcaklık aralıklarında farklı sürelerde (2-10 saat) ve farklı borlama ortamlarında gerçekleştirilir [9-11]. Bor işlemi neticesinde $\mathrm{FeB}, \mathrm{Fe}_{2} \mathrm{~B}$ veya $\mathrm{FeB}+\mathrm{Fe}_{2} \mathrm{~B}$ borür tabakaları demir esaslı metallerin yüzeyinde tek veya çift fazlı olarak ortaya çıkmaktadır [12]. Kutu borlama yönteminde bor verici tozlar içerisinde malzemenin kimyasal bileşimine, kalınlığına ve elde edilmek istenilen bor tabakası kalınlığına göre $800-1050{ }^{\circ} \mathrm{C}$ sıcaklıklar aralığında en az bir saat bekletilerek gerçekleştirilir [13-16]. Malzemenin kimyasal yapısına, borlama yöntemi ve şartlarına bağlı olarak borlanmış malzeme yüzeyindeki bor tabakası yaklaşık 2000 HV sertliğe sahip olabilmektedir. Elde edilen tabaka fazına bağlı olarak malzeme yüzeyi aşınma direnci kazanır [17,18]. Bu şekilde makine parçalarının kullanım ömürleri uzatılabilmektedir.

Bu çalışmada Hardox 500 çeliği, farklı sıcaklık ve bekletme sürelerinde kutu borlama yöntemi ile borlanmıştır. Borlama işlemi sonucunda Hardox 500 çeliğinin yüzey özelliklerinde, aşınma ve yapışma davranışlarındaki değişim incelenmiştir.

\section{MALZEME VE METOT}

\section{A. Malzemeler ve Borlama İşlemi}

Deneylerde kullanılan numuneler Ø15x6 mm ölçülerinde kesilerek 120-1200 grit zımpara aşamalarından geçilerek yüzeyleri borlama işlemi için hazırlanmıştır. Numuneler önce farklı sıcaklıklarda $\left(850,900,950{ }^{\circ} \mathrm{C}\right)$ ve her bir sıcaklıktaki farklı bekletme sürelerinde (2, 4, 6 saat) paslanmaz çelik potaya doldurulan ticari Ekabor-2 tozun içerisinde isıl işleme tabi tutulmuştur. Daha sonra numuneler oda sıcaklığına kadar kutu içerisinde soğutulmuş ve pota içerisinden çıkarılmıştır. Bu çalışmada kullanılan Hardox 500 çeliğin kimyasal bileşimi Tablo 1'de verilmiştir.

Tablo 1. Test malzemesinin kimyasal bileşimi

\begin{tabular}{cccccccccc}
\hline Çelik & $\mathbf{C}$ & $\mathbf{M n}$ & $\mathbf{C r}$ & $\mathbf{S i}$ & $\mathbf{M o}$ & $\mathbf{P}$ & $\mathbf{S}$ & $\mathbf{B}$ & $\mathbf{N i}$ \\
\hline Hardox 500 & 0.3 & 1.6 & 1.5 & 0.7 & 0.6 & 0.02 & 0.001 & 0.005 & 0.15 \\
\hline
\end{tabular}

Borlama 1sıl işlem sonrasında hassas numune kesme cihazında numuneler kesilmiştir. Numune yüzeyleri metalografik yöntemlere uygun olarak önce 120-1200 Grit kum zımpara kağıtlarında aşındırılmış ve sonrasında 1 $\mu \mathrm{m}$ alümina süspansiyon ile parlatılmıştır. Ardından numuneler \% 3 Nital asitli çözeltide dağlanıştır. Numuneler Rockwel-C yöntemi ile yapılan yapışma kalitesi testi için LEO 1430 VP marka SEM mikroskobu ile incelenmiştir. Bor tabakasındaki fazlar, CuKa $(\lambda=1.5406$ A) radyasyonu kullanılarak Shimadzu XRD-6000 marka X-ışını kırınımı ile belirlenmiştir. Borür kaplama tabaka kalınlığı, bir optik mikroskoba bağlanan dijital kalınlık ölçüm cihazı ile ölçülmüştür. Numunelerin Vickers sertlik değerleri Shimadzu HM-2 mikro sertlik cihazında 50 gr. yük altında Vickers uç kullanılarak belirlenmiştir. 


\begin{tabular}{|c|c|c|}
\hline & $\begin{array}{l}\text { BŞEÜ Fen Bilimleri Dergisi } \\
8(1), 151-158,2021\end{array}$ & $\begin{array}{r}\text { BSEU Journal of Science } \\
\text { https://doi.org/10.35193/bseufbd } 852948\end{array}$ \\
\hline ERS & & 2458-7575 (https://dergipark.org.tr/tr/pub/bseufbd) \\
\hline
\end{tabular}

\section{B. Yapışma ve Aşınma Testi}

Kaplama sonrası oluşan bor tabakasının yapışma mukavemeti VDI 3198 normu ile Daimler-Benz Rockwell-C yapışma testi kullanılarak değerlendirilmiştir. VDI 3198 standardı Şekil 1' de gösterilmiştir [19]. Şekil 1' de kaplamalar için kabul edilebilir veya zayıf yapışma sınıflandırmaları Rockwell-C indentörünün batıcı ucunun sonuçlarına dayalı görülmektedir. Rockwell-C girinti testi $1471 \mathrm{~N}$ yük altında her numune için üç adet girinti testi uygulanmıştır. Test sonuçları SEM mikroskobu görüntüsü ile değerlendirilmiştir.

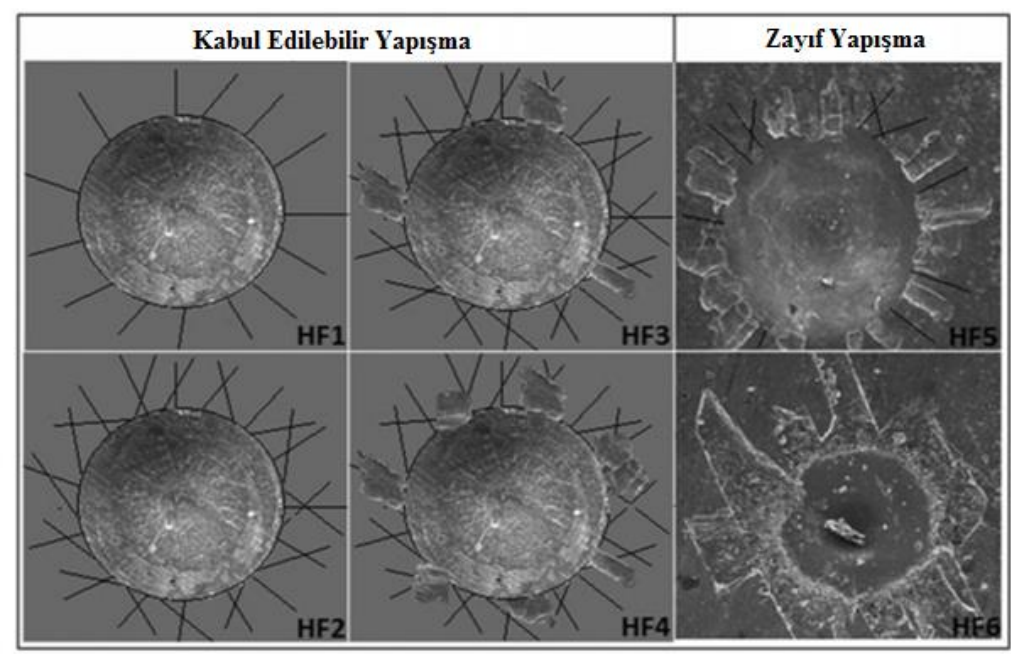

Şekil 1. VDI3198 standartına göre kaplamaların yapışma kalitesi

Kutu borlanmış Hardox 500 çeliğinin aşınma özellikleri bilyeli disk aşınma cihazı kullanılarak belirlenmiş̧tir. Aşınma deneyinde $8 \mathrm{~mm}$ çaplı WC-Co bilyesi kullanılmıştır. Aşınma deneyi 10N yük altında oda sıcaklığında ve $0,3 \mathrm{~m} / \mathrm{s}$ kayma hızında kuru ortam şartlarında 500 metre uzunluğuna karşılık gelen kaydırma uzunluğu boyunca gerçekleştirilmiştir. Aşınma oranı Rugosimeter marka pürüzlülük cihazı belirlenmiştir. Aşınma hacminin hesaplandığı formül ise Denklem 1' de verilmiştir.

Aşınma Hızı = Aşınma Hacmi / (Uygulama Yükü x Kayma Mesafesi) $\left(\mathrm{mm}^{3} / \mathrm{Nm}\right)$

\section{BULGULAR VE TARTIȘMA}

\section{A. Bor Kaplamanin Karakterizasyonu}

850,900 ve $950{ }^{\circ} \mathrm{C}^{\prime}$ de 4 saat süre ile borlanmış Hardox 500 çeliklerin mikroyapıları Şekil 2' de gösterilmiş̧ir. Hardox 500 çeliğinin borlama işlemi neticesinde oluşan borür tabakasının parça yüzeyinden merkezine doğru uzanan testere dişi formunda olduğu görülmektedir (Şekil 2). Bu oluşan testere dişi morfoloji tabaka formu yüksek alaşımlı çeliklerin kutu borlanmasında da görülmüştür [20].

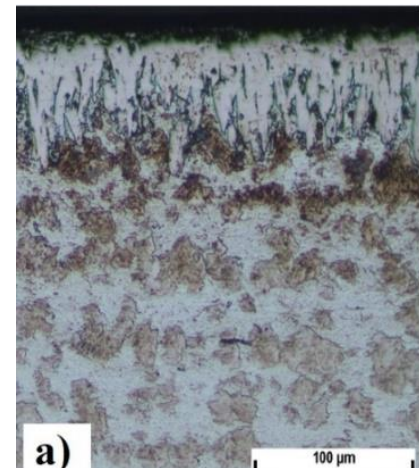

a)

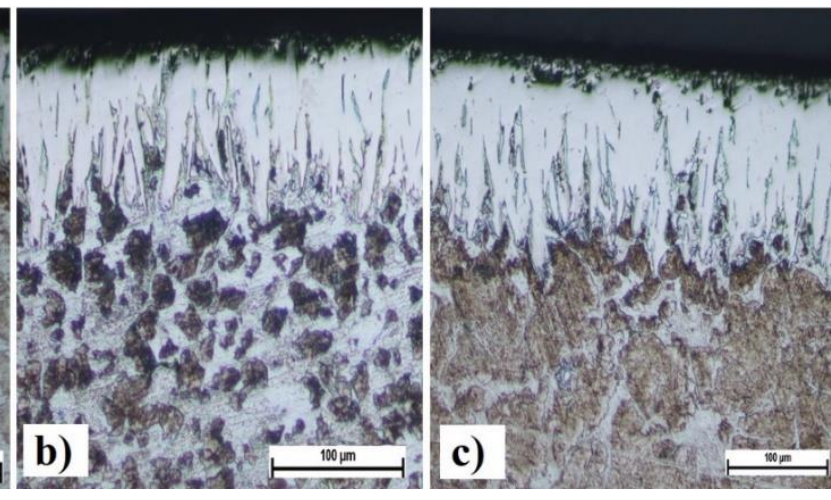

c)

Şekil 2. Hardox 500 çeliklerin 4 saat süre ile a) $850^{\circ} \mathrm{C}$ b) $900{ }^{\circ} \mathrm{C}$ c) $950{ }^{\circ} \mathrm{C}^{\prime}$ de borlanmış mikroyapıs 


\section{B. X-IŞııı Kırınım Analizi}

X-ışınları kırınım deseni grafiği Şekil 3' te gösterilmiştir. XRD analizi sonucunda 4 saat süre ile 850, 900 ve $950{ }^{\circ} \mathrm{C}$ sıcaklıklarda borlanmış Hardox 500 çeliklerinin yüzeyinde $\mathrm{Fe}_{2} \mathrm{~B}$ borür tabakasının oluştuğu görülmüştür. Genel olarak çeliklerin borlanması ile $\mathrm{FeB}$ ve $\mathrm{Fe}_{2} \mathrm{~B}$ ikili faz tabakasının oluşumu yapılan $\mathrm{XRD}$ analizlerinde görülmektedir. Oluşan iki fazlı yapı durumunda $\mathrm{FeB}$ fazı çekme çalışırken $\mathrm{Fe}_{2} \mathrm{~B}$ fazı ise basma etkisi göstermektedir. $\mathrm{Bu}$ farklı gerilme altındaki durumda fazlar arasında boşluk oluşumu ve dökülmeler görülebilmektedir. Bu etki FeB fazının sert ve gevrek yapısından da kaynaklandığı düşünülebilir. Çalışmada oluşan $\mathrm{Fe}_{2} \mathrm{~B}$ tek fazlı yapısı özellikle yapılan çalışmalarda istenilen bir durumdur [21].
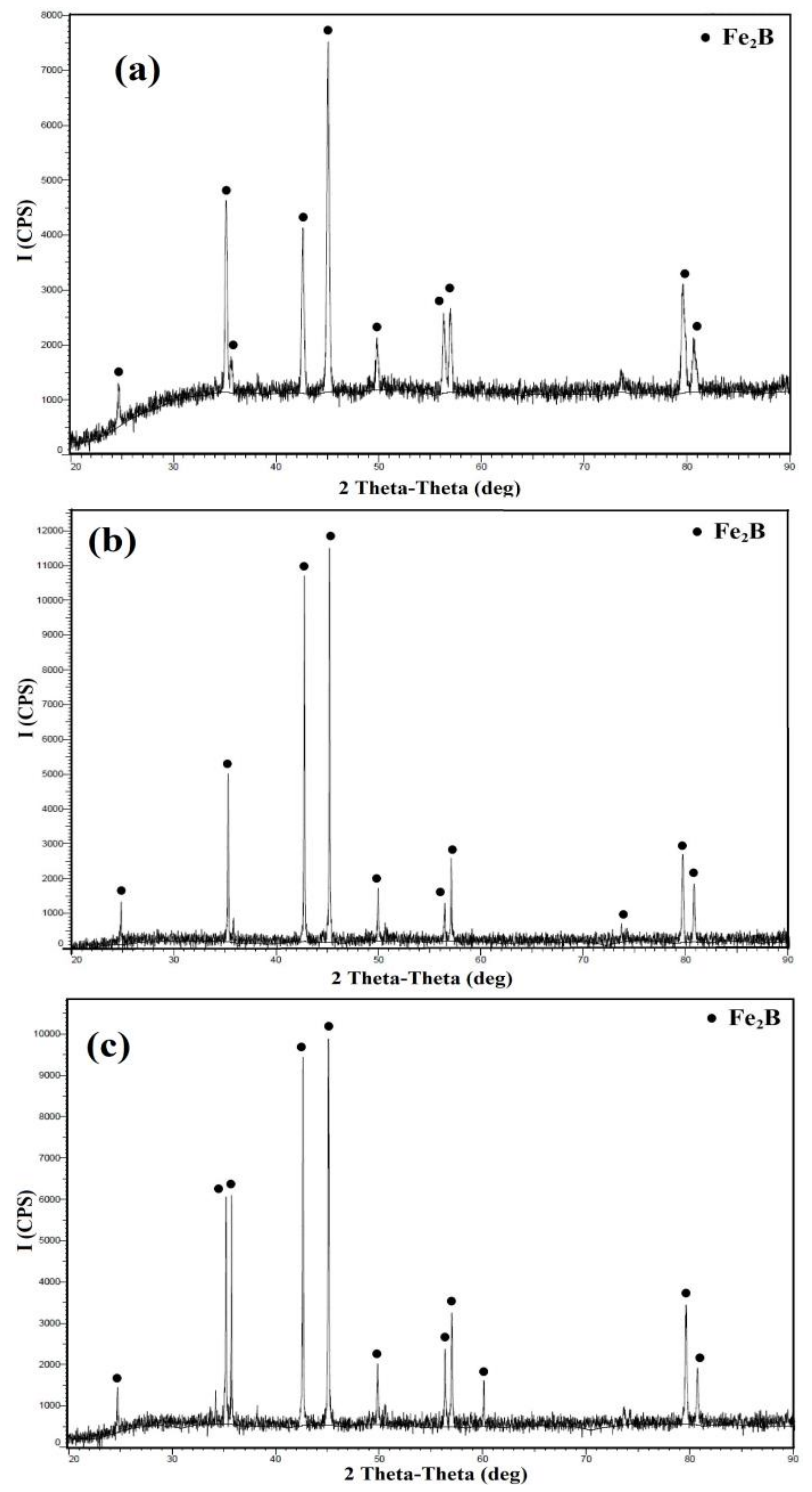

Şekil 3. Hardox 500 çeliklerin 4 saat süre ile borlanmış a) $850{ }^{\circ} \mathrm{C}$ b) $900{ }^{\circ} \mathrm{C}$ c) $950{ }^{\circ} \mathrm{C} \mathrm{X}$-ışınları difraksiyon analizi

\section{Borür Tabaka Kalınlığı ve Mikrosertlik Analizi}

Borür tabaka kalınlığı, malzemenin kimyasal bileşimi, borlama yöntemi, sıcaklığı ve süresine göre değişmektedir [22]. Genel olarak artan sıcaklık ve süre ile doğru orantılı olarak tabaka kalınlığı artmaktadır. Hardox 500 çeliklerin yüzeyinde borlama ısıl işlem sıcaklığı ve süresine göre elde edilen borür tabaka kalınlıkları Şekil 4' de gösterilmiştir. Kaplama taba kalınlığının 40-120 $\mu \mathrm{m}$ arasında değiştiği görülmektedir (Şekil 4). 


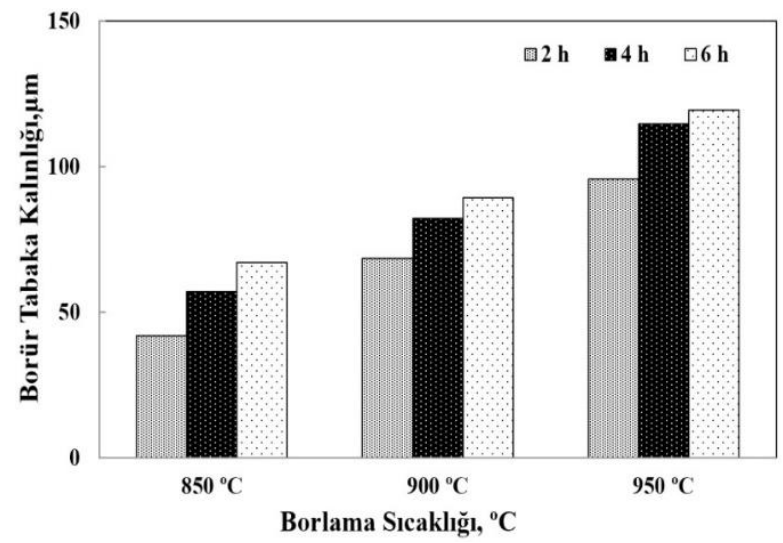

Şekil 4. Hardox 500 çeliklerin borlama sıcaklık ve süresine bağlı olarak borür tabaka kalınlığı değişimi

Şekil 5' te Hardox 500 çeliklerin kutu borlama işlemi sonucunda malzemenin yüzeyinden belirli mesafedeki mikrosertlik değişimi gösterilmiştir. Sertlik değerlerindeki değişim borlama süresi ve sıcaklığı ile oluşan borür fazına göre değişecektir [22]. En yüksek sertlik değeri oluşan $\mathrm{Fe}_{2} \mathrm{~B}$ faz bölgesinde malzemenin en diş yüzeyi bölgesinde elde edilmiştir. Malzemenin matris bölgesi yaklaş1k $400 \mathrm{HV}_{0,05}$ iken numune yüzeyindeki borür tabakası yaklaşık $1850 \mathrm{HV}_{0,05}$ olduğu gözlemlenmiştir.

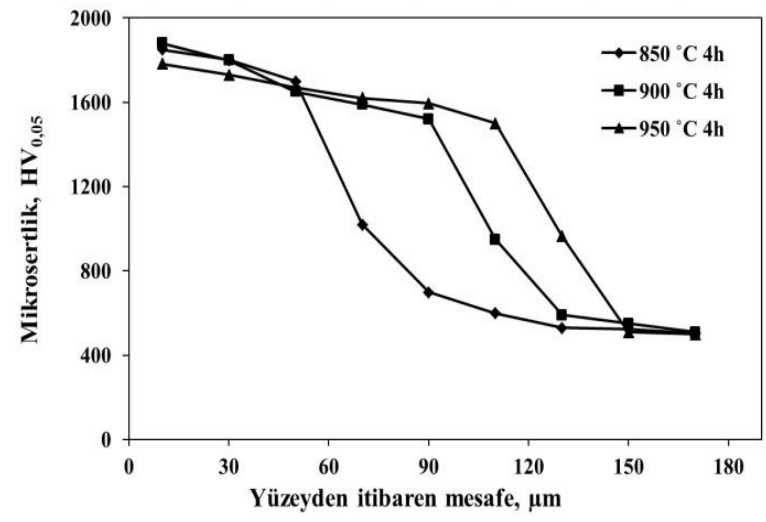

Şekil 5. Hardox 500 çeliklerin borlama sıcaklık ve süresine bağlı olarak mesafeye göre mikrosertlik değişimi

\section{Aşınma ve Yapışma Analizi}

Şekil 6'da farklı süre ve sıcaklıklarda borlanmış Hardox 500 çelik numunelerin aşınma hızı ve sürtünme katsayısı gösterilmiştir. Elde edilen sonuçlarda en düşük sürtünme katsayısı ve aşınma hız1 $850{ }^{\circ} \mathrm{C} 2$ saat süre ile borlanmış numunelerde elde edilmiştir. Artan borlama sıcaklığı ve süresi ile sürtünme katsayısı ve aşınma hızı da artmıştır. Artan sıcaklık ve bekletme süresi ile tabaka kalınlığı artarken aşınma oranın da arttığı görülmektedir [23]. 


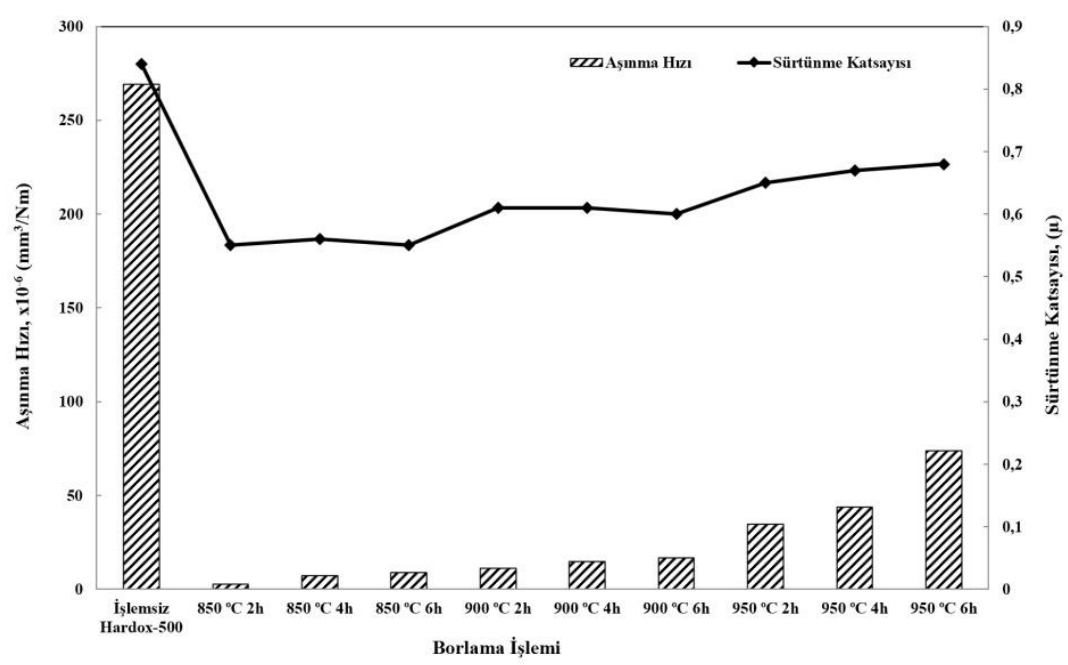

Şekil 6. Hardox 500 çeliğinin sürtünme katsayısı ve aşınma hızı grafiği

Şekil 7' de aşınma testi sonucunda elde edilen aşınma izlerinin yüzey profilleri gösterilmiştir. Elde edilen yüzey izlerine göre en geniş aşınma yüzeyi işlemsiz ilk durumdaki Hardox 500 çeliğinde elde edilmiştir. En dar iz genişliği ise $850{ }^{\circ} \mathrm{C} 2$ saat borlanmış Hardox 500 çelik numunesinde elde edilmiştir. $850{ }^{\circ} \mathrm{C} 2$ saat borlanmış numunenin yüzey iz genişliği aşınma hızı ve sürtünme katsayısı ile uyumlu olduğu gözlemlenmiştir.
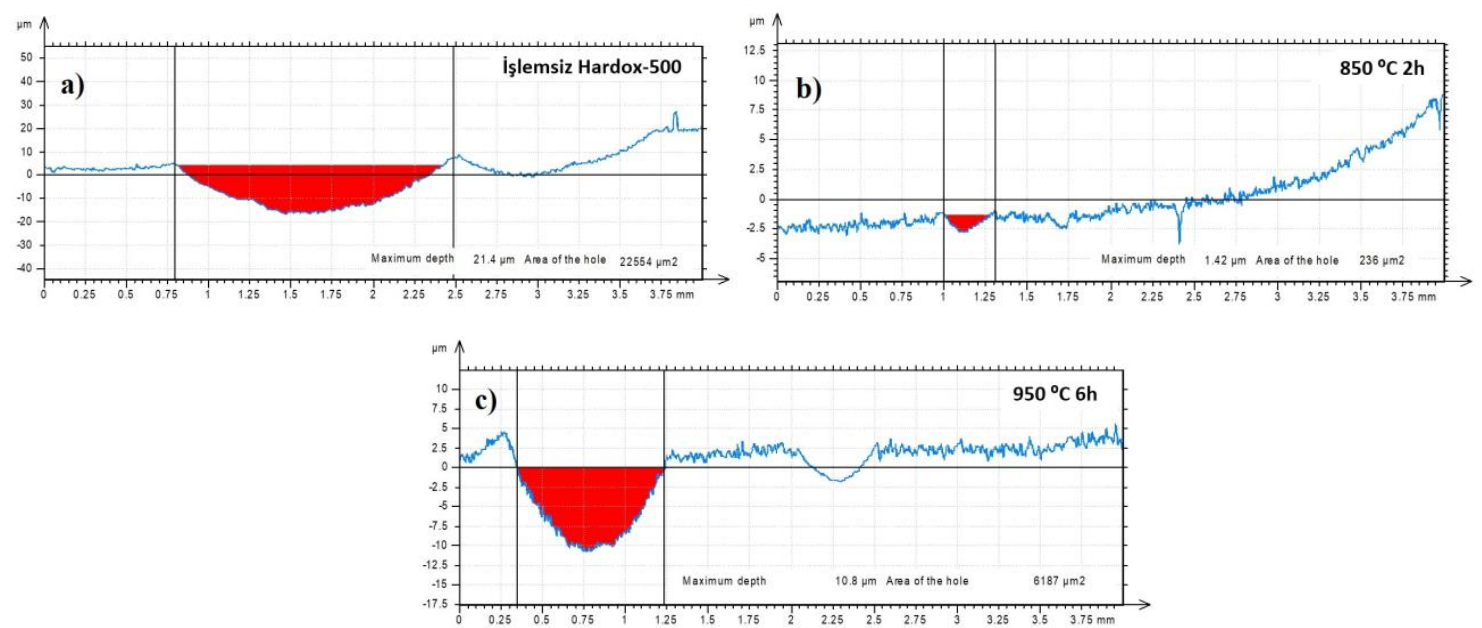

Şekil 7. Hardox 500 çeliğinin aşınma yüzey profili a) işlemsiz b) $850{ }^{\circ} \mathrm{C} 2$ saat borlanmış c) $950{ }^{\circ} \mathrm{C} 6$ saat borlanmış

Rockwell-C girinti testi sonucunda elde edilen görüntüler Şekil 8' de gösterilmiştir. Şekil 8' de borlanmıŞ Hardox 500 numuneleri arasında aşınma testi sonuçlarında en düşük aşınma hızı ve sürtünme katsayısına sahip $850{ }^{\circ} \mathrm{C} 2$ saat borlanmış numune ve en yüksek aşınma hızı ve sürtünme katsayısına sahip $950{ }^{\circ} \mathrm{C} 6$ saat borlanmış numune SEM mikroskobu görüntüsü gösterilmiştir. $850{ }^{\circ} \mathrm{C} 2$ saat borlanmış numune Rockwell-C girinti testi sonucunda mikro çatlakların oluştuğu ve Daimler Benz test haritasına göre HF1'e uygun olduğu gözlemlenmiştir. $950{ }^{\circ} \mathrm{C} 6$ saat borlanmış numune de ise hem delaminasyonlar hem de mikro çatlakların oluştuğu ve Daimler Benz test haritasına göre HF5'e uygun olduğu gözlemlenmiştir. Borlama sıcaklığının ve süresinin artırılmasıyla elde edilen borür tabakasının yapışma kalitesi hem aşınma testine hem de Rockwell-C girinti testi sonuçlarına göre azalmaktadır [22]. 


\begin{tabular}{|c|c|c|}
\hline & $\begin{array}{l}\text { BŞEÜ Fen Bilimleri Dergisi } \\
8(1), 151-158,2021\end{array}$ & $\begin{array}{r}\text { BSEU Journal of Science } \\
\text { https://doi.org/10.35193/bseufbd } 852948\end{array}$ \\
\hline ERS & & 2458-7575 (https://dergipark.org.tr/tr/pub/bseufbd) \\
\hline
\end{tabular}

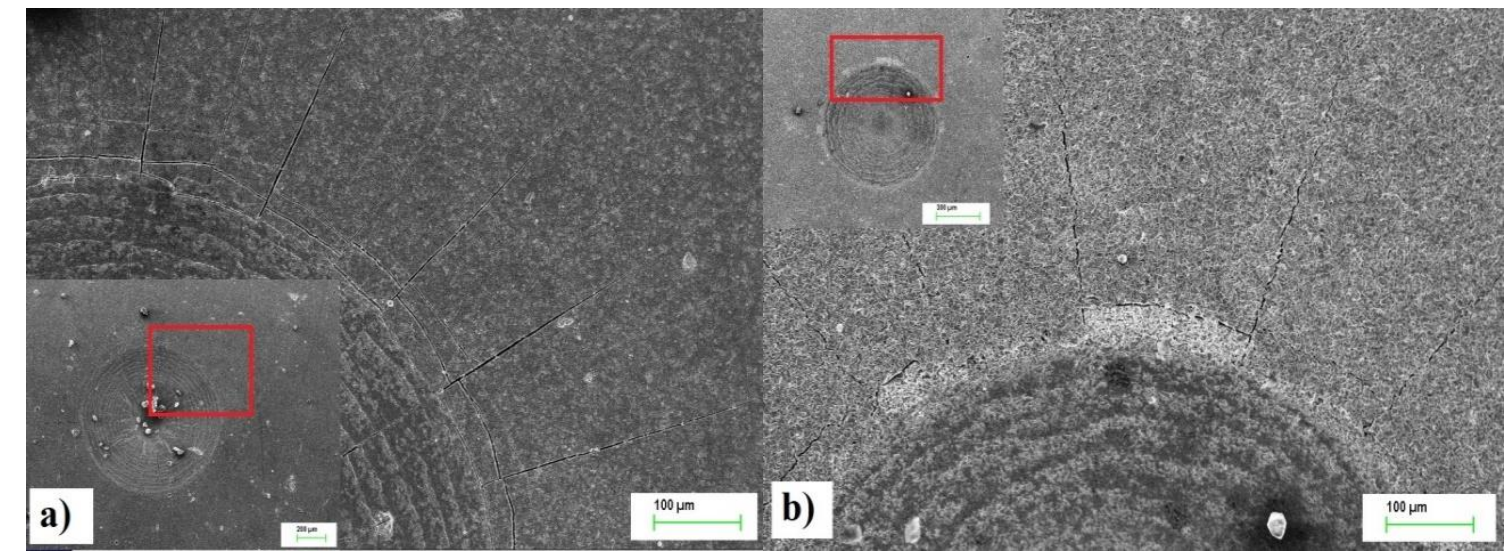

Şekil 8. Borlanmış Hardox 500 çeliğin Rockwell-C Yapışma Testi SEM görüntüsü a) $850{ }^{\circ} \mathrm{C} 2$ saat b) $950{ }^{\circ} \mathrm{C} 6$ saat

\section{SONUÇLAR}

Hardox 500 çeliğinin kutu borlama yöntemi kullanılarak $850^{\circ} \mathrm{C}, 900^{\circ} \mathrm{C}, 950^{\circ} \mathrm{C}$ sıcaklıklarında 2,4 ve 6 saat süreyle borlanmasiyla;

Kaplama tabakasının testere dişi morfolojisinde oluşmuştur. Kaplama tabakası kalınlığı 40-120 $\mu \mathrm{m}$ arasında değişmiştir. En yüksek kaplama kalınlığ $950^{\circ} \mathrm{C} 6$ saat süreyle borlanmış numunede elde edilmiştir. Artan borlama sıcaklığı ve süresiyle kaplama kalınlığı artmıştır. XRD analizinde kaplama tabakasının tek fazlı $\mathrm{Fe}_{2} \mathrm{~B}$ olduğu tespit edilmiştir. Borlama işlemi sonucunda kaplama tabakasının sertliği $1850 \mathrm{HV}_{0,05}$ olduğu tespit edilmiştir. Bu değer işlemsiz ilk hale göre 4,5 kat daha yüksektir. Aşınma testi sonucunda en iyi aşınma direnci $850^{\circ} \mathrm{C} 2$ saat süre ile borlanmış numunedir. Aynı numunenin yüzey iz genişliği ve aşınma hacmi de düşük çıkmıştır. En düşük aşınma direnci ise $950^{\circ} \mathrm{C} 6$ saat süre ile borlanmış numunede elde edilmiştir. $850{ }^{\circ} \mathrm{C} 2$ saat sürede borlanmış numuneler Rockwell-C girinti testi sonucuna göre uygun yapışma kalitesine sahiptir.

\section{KAYNAKLAR}

[1] Adamiak, M., Górka, J. \& Kik, T. (2009). Comparison of abrasion resistance of selected constructional materials. Journal of Achievements in Materials and Manufacturing Engineering, 37(2), 375-380.

[2] Mindivan, H. (2013). Effects of combined diffusion treatments on the wear behaviour of hardox 400 steel. Procedia Engineering, 68, 710-715.

[3] Anonim, (2020). SSAB. https://www.ssab.com.tr/api/sitecore/Datasheet/GetDocument (Erişim Tarihi: 17.12.2020).

[4] Kayalı Y. \& Kara R., (2019). Borlanmış Hardox Çeliklerinin Difüzyon Kinetiklerinin İncelenmesi. The Internatinonal Conference on Materials Science, Mechanical and Automotive Engineerings and Technology, 21-23 Haziran 2019, Nevşehir.

[5] Tabur M. \& İzciler M., (2019). Hardox 500 ve Hardox 600 Çeliklerinin Abrasiv Aşınma Davranışlarının Karşılaştırılması. ISAS 2019, 19-21 Nisan 2019, Ankara.

[6] Teker, T., Karataş, S. \& Yilmaz, S. O. (2014). Microstructure and wear properties of AISI 1020 steel surface modified by HARDOX 450 and FeB powder mixture. Protection of Metals and Physical Chemistry of Surfaces, 50(1), 94-103.

[7] Hacısalihoğlu, İ., Yıldız, F. \& Çelik, A. (2018). Tribocorrosion behavior of plasma nitrided Hardox steels in $\mathrm{NaCl}$ solution. Tribology International, 120, 434-445.

[8] Gromov, V. E., Kormyshev, V. E., Glezer, A. M., Konovalov, S. V., Ivanov, Y. F., \& Semin, A. P. (2018, September). Microstructure and wear properties of Hardox 450 steel surface modified by Fe-C-Cr-Nb-W powder wire surfacing and electron beam treatment. In IOP Conference Series: Materials Science and Engineering , 411(1), 012024

[9] Çelikyürek, İ., Baksan, B., Torun, O. \& Gürler, R. (2006). Boronizing of iron aluminide Fe72Al28. Intermetallics, 14(2), 136-141.

[10] Bejar, M. A., \& Moreno, E. (2006). Abrasive wear resistance of boronized carbon and low-alloy steels. Journal of Materials Processing Technology, 173(3), 352-358.

[11] Kayalı, Y. (2015). Investigation of diffusion kinetics of borided AISI P20 steel in micro-wave furnace. 
[12] Özsoy, A. (2001). Borlama ile ilgili genel bir değerlendirme. Endüstriyel Yüzey Teknolojileri Dergisi, Sayl, 22, 10-13.

[13] Sinha A K, 1991. Boronizing. ASM Materials Handbook 4, ASM International

[14] Hunger, H. J. \& Trute, G. (1994). Boronizing to produce wear resistant surface layers. Heat Treatment of Metals (UK), 21(2), 31-39.

[15] Karakan, M., Alsaran. A. \& Çelik. A, (2002). Plazma Borlama, Mühendis ve Makine, 43(512), 51-54.

[16] Er, Ü. (2004). Bor yayınımıyla yüzeyi sertleştirilmiş AISI 1030 ve AISI 1050 çeliklerinin abrazif aşınma dayanımlarının incelenmesi. Osmangazi Üniversitesi Mühendislik Mimarlık Fakültesi Dergisi, 17(1), 1-12.

[17] Atık, E., Yunker, U. \& Merıç, C. (2003). The effects of conventional heat treatment and boronizing on abrasive wear and corrosion of SAE 1010, SAE 1040, D2 and 304 steels. Tribology International, 36(3), $155-161$.

[18] Barut, N., Yavuz, D. \& Kayali, Y. (2014). Borlanmış AISI 5140 ve AISI 420 Çeliklerinin Difüzyon ve Adhezyon Davranışlarının İncelenmesi (015701) (1-8). Afyon Kocatepe Üniversitesi Fen ve Mühendislik Bilimleri Dergisi, 14(1), 1-8.

[19] Anonim, (1992). Daimler Benz adhesion test, Richtlinien, No. 3198, Verein Deutscher Ingenieure (VDI), Dusseldorf: VDI-Verlag, 7-12.

[20] Efe, G. Ç., İpek, M., Özbek, İ. \& Bindal, C. (2008). Kinetics of borided 31CrMoV9 and 34CrAlNi7 steels. Materials characterization, 59(1), 23-31.

[21] Delikanlı, K., Çalık, A., \& Uzun, H. A. (2002). Sade karbonlu bir çeliğin borlama özelliklerinin incelenmesi. Ballkesir Üniversitesi Fen Bilimleri Enstitüsü Dergisi, 5(1), 99-110.

[22] Kayal1, Y. (2013). Investigation of the diffusion kinetics of borided stainless steels. The physics of metals and metallography, 114(12), 1061-1068.

[23] Meriç, C., Şahin, S., Backir, B., \& Köksal, N. S. (2006). Investigation of the boronizing effect on the abrasive wear behavior in cast irons. Materials \& Design, 27(9), 751-757. 